International Journal of Ophthalmology \& Eye Science (IJOES)

ISSN 2332-290X

\title{
The Effect Of Preservative Free Tafluprost On Intraocular Pressure In Patients With Ocular Hypertension Or Primary Open Angle Glaucoma
}

\author{
Clinical Trial
}

Hommer $\mathrm{A}^{1,2}$, Kromus $\mathrm{M}^{2}$, Schmidl $\mathrm{D}^{1}$, Garhofer $\mathrm{G}^{1 *}$, Schmetterer $\mathrm{L}^{1,3}$

${ }^{1}$ Department of Clinical Pharmacology, Medical University of Vienna, Austria

${ }^{2}$ Department of Ophthalmology, Sanatorium Hera, Vienna, Austria

${ }^{3}$ Center for Medical Physics and Biomedical Engineering, Medical University of Vienna, Austria.

\begin{abstract}
Purpose: Increased intraocular pressure (IOP) is the most important modifiable risk factor for the development and progression of glaucoma. This underlines the need for a potent and save IOP lowering therapy. The introduction of preservative free prostaglandins offers a new treatment possibility using a potent topical drug without the disadvantages of a coadministered preservative. The current study was designed to investigate the effect of an 8 week treatment with preservative free tafluprost on IOP in patients with glaucoma or ocular hypertension.

Methods: 16 patients with either primary open angle glaucoma or ocular hypertension with an uncontrolled intraocular pressure $(\mathrm{IOP}) \geq 30 \mathrm{mmHg}$ were included in the study. A washout period with a duration between 2 and 4 weeks was scheduled for all patients before study start. IOP was measured at 8:00am and 6:00pm on each study day. IOP measurements were performed after the washout period as well as 4 and 8 weeks after start of topical drug treatment.

Results: After the 2-4 weeks washout period average IOP was $35.6 \pm 4.5 \mathrm{mmHg}$ at 8:00 am and $32.9 \pm 5.4 \mathrm{mmHg}$ at 6:00 pm. After 4 weeks administration of preservative free tafluprost, IOP decreased by $31 \% \pm 12 \%$ to $24.4 \pm 4.6 \mathrm{mmHg}(\mathrm{p}<0.01)$ and by $34 \% \pm 14 \%$ to $21.6 \pm 4.6 \mathrm{mmHg}(\mathrm{p}<0.01)$ at the morning and evening, respectively. At 8 weeks of tafluprost treatment IOP was $24.3 \pm 4.6 \mathrm{mmHg}$ at $8: 00 \mathrm{am}(-31 \% \pm 13 \%$ compared to baseline, $\mathrm{p}<0.01)$ and $21.9 \pm 3.9 \mathrm{mmHg}$ at $6: 00 \mathrm{pm}$ $(-32 \% \pm 16 \%$ compared to baseline, $\mathrm{p}<0.01)$. No significant difference was observed in IOP change between 4 and 8 weeks at either time point.

Conclusion: Our data indicate that treatment with preservative free tafluprost is a safe and potent therapy to lower IOP in patients with primary open angle glaucoma and ocular hypertension. In this group of patients with relatively high IOPs at baseline a pronounced reduction of IOP was achieved over a period of 4 to 8 weeks.
\end{abstract}

Key Words: Glaucoma; Intraocular Pressure; Ocular Hypertension; Preservative-Free; Tafluprost.

\section{*Corresponding Author:}

Dr. Gerhard Garhöfer,

Department of Clinical Pharmacology, Medical University of Vienna,

Austria, Währinger Gürtel 18-20, A-1090 Vienna, Austria.

Tel: $++43-1-40400-2981$

Fax: ++43-1-40400-2998

E-mail: gerhard.garhoefer@meduniwien.ac.at

Received: March 03, 2015

Accepted: March 31, 2015

Published: April 02, 2015

Citation: Garhofer G, et al., (2015) The Effect of Preservative Free Tafluprost on Intraocular Pressure in Patients with Ocular Hypertension or Primary Open Angle Glaucoma. Int J Ophthalmol Eye Res. S1:006, 27-31. doi: http://dx.doi.org/10.19070/2332-290X-SI01006

Copyright: Garhofer $\mathbf{G}^{\odot}$ 2015. This is an open-access article distributed under the terms of the Creative Commons Attribution License, which permits unrestricted use, distribution and reproduction in any medium, provided the original author and source are credited.

\section{Introduction}

Glaucoma is characterized by the loss of retinal ganglion cells and associated axons, which becomes clinically manifest in visual field deterioration [1]. Given that increased intraocular pressure (IOP) is the most important risk factor for the development and progression of the disease [2], lowering of the IOP is currently the only proven therapy for the treatment of glaucoma. This has been demonstrated in several large interventional studies, showing that lowering IOP slows down the progression of the disease [3].

Although for a long time, beta-blockers were the mainstay of therapy aiming to lower IOP, prostaglandin analogues are more and more often used as the first-line therapy in the treatment of primary open-angle glaucoma. Prostaglandin analogues are known for their potent IOP lowering effect by increasing the aqueous humor outflow [4]. In addition, prostaglandin analogues show only a low risk of side effects and allow for a once-a-day instillation, both of which are major determinants of patients' compliance. 
Although prostaglandins have proven to be safe and well tolerated, data from clinical studies indicate that preservatives, which are added to multi-dose bottles to inhibit the growth of microbial contaminants, may have adverse effects in long term use [5]. In particular, benzalkonium chloride may affect the ocular surface and exacerbate symptoms of chronic ocular surface disease [6]. Recently, the introduction of preservative free prostaglandin analogues has offered the possibility of topical prostaglandin treatment without the concomitant use of preservatives [7]. In this study we focus on the IOP lowering potency of tafluprost preservative free eyedrops in patients with ocular hypertension and with primary open angle glaucoma and an untreated IOP of 30 $\mathrm{mmHg}$ and more.

\section{Materials and Methods}

\section{Patients}

The study protocol was approved by the Ethics Committee of the City of Vienna and followed the guidelines of Good Clinical Practice and the Declaration of Helsinki. 16 patients with either primary open angle glaucoma or patients with ocular hypertension were included in the study. All patients signed a written informed consent form and passed an ophthalmologic examination including gonioscopy and visual field testing with the Octopus Perimeter. Patients with ocular disease other than glaucoma or ocular hypertension were excluded from the study. Further, patients with topical treatment with any ophthalmic drug in the 4 weeks preceding the first study visit except glaucoma medication or topical lubricants were not included in the study.

\section{Inclusion and Exclusion Criteria}

Patients with primary open angle glaucoma (POAG): Inclusion criteria were POAG defined as pathological optic disc appearance and characteristic visual field loss, ametropia of less than 3 diopters, and anisometropia of less than 1 diopter. Only patients with an untreated IOP of $30 \mathrm{mmHg}$ or more were included in the study. Any of the following excluded a glaucoma patient from participation in the trial: exfoliation glaucoma, pigmentary glaucoma, history of acute angle closure, mean deviation (MD) of visual field testing of $15 \mathrm{~dB}$ or worse or intraocular surgery within the last 6 months.

Patients with ocular hypertension: Ocular hypertension was defined as an untreated IOP of $30 \mathrm{mmHg}$ or more without any glaucomatous changes in either the visual field or the optic disc appearance.

\section{Experimental Paradigm}

For eligible patients, current ocular hypotensive treatment was suspended prior to the baseline visit for 2 to 4 weeks if applicable. Three study visits were scheduled for all participating patients. At each visit, IOP was measured twice in the study eye at 8:00 am and 6:00 pm.

\section{Intraocular pressure}

A slit-lamp mounted Goldmann applanation tonometer (Haag Streit, Switzerland) was used to measure IOP. Before each measurement, one drop of $0.4 \%$ benoxinate hydrochloride combined with $0.25 \%$ sodium fluorescein was used for local anesthesia of the cornea. All IOP measurements were performed by the same person.

\section{Pachymetry}

Corneal thickness was determined by a pachymeter (Pachette II, DGH Technology Inc., USA). Using an ultrasound probe at a frequency of $65 \mathrm{MHz}$, the pachymeter is able to determine the thickness of the cornea in any given location. The probe touches the corneal surface under local anesthesia.

\section{Statistics}

Data are presented as means $\pm \mathrm{SD}$. Statistical analysis was done as a "per protocol" analysis. Statistical significant effects were assessed within a repeated measures ANOVA model. A $p<0.05$ was considered as the level of significance. Calculations were performed using the Statistica ${ }^{\circledR}$ software package (Statsoft, USA).

\section{Results}

16 patients (mean age $62.3 \pm 11.8$ years) were included in the study. Baseline characteristics of the patients are given in Table 1.

After the 2-4 week washout period average IOP was 35.6 \pm 4.5 $\mathrm{mmHg}$ at the morning and $32.9 \pm 5.4 \mathrm{mmHg}$ at the evening measurement. As shown in figures 1 and 2, 4 weeks after the start of treatment preservative free tafluprost decreased IOP by $31 \% \pm 12 \%$ to $24.4 \pm 4.6 \mathrm{mmHg}(\mathrm{p}<0.01)$ at the morning and by $34 \% \pm 14 \%$ to $21.6 \pm 4.6 \mathrm{mmHg}(\mathrm{p}<0.01)$ at the evening.

8 weeks after start of treatment, IOP was still low, amounting to $24.3 \pm 4.6 \mathrm{mmHg}(-31 \% \pm 13 \%$ compared to baseline, $\mathrm{p}<0.01)$ in the morning and $21.9 \pm 3.9 \mathrm{mmHg}(-32 \% \pm 16 \%$ compared to baseline, $\mathrm{p}<0.01$ ) in the evening (Figures 1 and 2). No significant difference was observed in terms of IOP change between 4 and 8 weeks of treatment at neither of the two measurement times ( $p=0.9$ for the morning measurement; $p=0.8$ for the evening measurement).

No serious adverse events were observed. A total of 12 adverse

Table 1. Baseline characteristics of the study population at the screening examination. Values are given as means \pm SD.

\begin{tabular}{|c|c|}
\hline Age (years) & $62.3 \pm 11.8$ \\
\hline Mean deviation $(\mathrm{dB})$ & $1.4 \pm 3.7$ \\
\hline Intraocular pressure $(\mathrm{mmHg})$ & $28 \pm 5$ \\
\hline Central corneal thickness $(\mu \mathrm{m})$ & $543 \pm 43$ \\
\hline Gonioscopy grading (Shaffer classification) & $3.6 \pm 0.5$ \\
\hline Visual acuity (Snellen) & $0.73 \pm 0.21$ \\
\hline
\end{tabular}


events occurred in 8 of the 16 patients during the study. All events were mild and 4 were judged as possibly related and 1 as unlikely related to the study medication. All other adverse events were judged as not related to the study medication. A listing of all adverse events observed is given in Table 2.

\section{Discussion}

Given that IOP lowering therapy is usually a life-time or at least a long-time treatment, preservative free prostaglandin treatment offers several major advantages for patients. These advantages

Figure 1. Intraocular pressure during the course of the study (* significant changes vs. baseline). Values are shown as means \pm SD

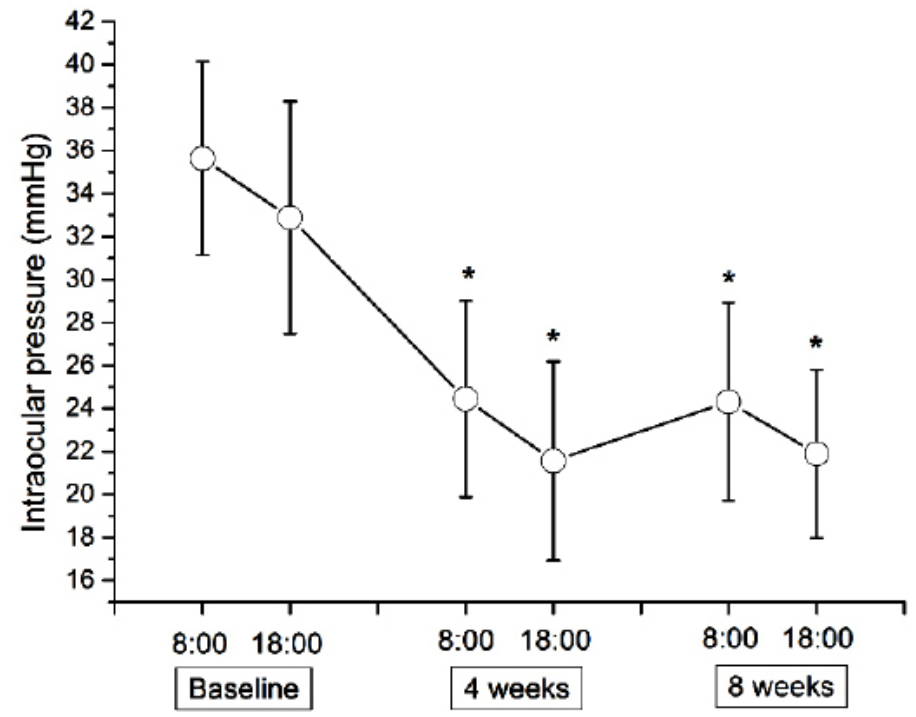

Figure 2. Relative change in intraocular pressure after 4 and 8 weeks compared to baseline $(*$ significant changes vs. baseline). Values are shown as means $\pm \mathrm{SD}$.

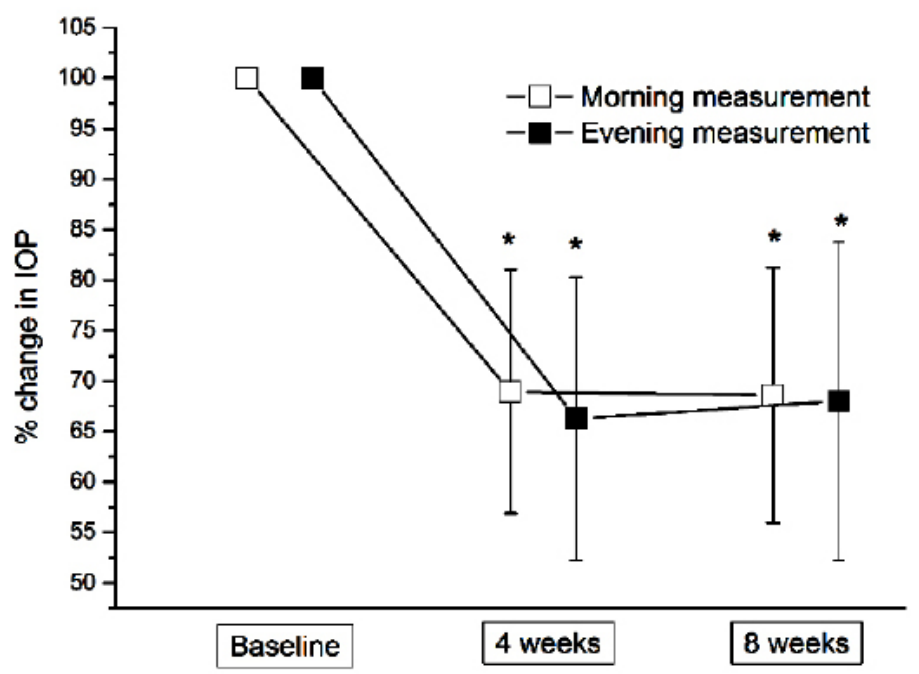

Table 2. Summary of all Adverse Events that occurred during the study.

\begin{tabular}{|c|c|c|c|}
\hline Adverse Event & Times observed & Severity & Relationship to Medication \\
\hline \multicolumn{4}{|c|}{ Ocular Adverse Events } \\
\hline Itching after instillation & 1 & Mild & Possible \\
\hline Hyperemia in both eyes & 1 & Mild & Possible \\
\hline Burning after instillation & 1 & Mild & Possible \\
\hline Light sensitivity & 1 & Mild & Possible \\
\hline Blepharitis & 1 & Mild & Unlikely \\
\hline \multicolumn{5}{|c|}{ Non-ocular Adverse Events } \\
\hline Common cold & 2 & Mild & Unrelated \\
\hline Rhinitis & 2 & Mild & Unrelated \\
\hline Gingivitis & 1 & Mild & Unrelated \\
\hline Stomal mucosa wound & 1 & Mild & Unrelated \\
\hline Exanthema and pruritus (limbs) & 1 & Mild & Unrelated \\
\hline
\end{tabular}


include a reduced exposure to preservatives, enhanced patient compliance and a reduction of the number of drops instilled [8, 9]. The data of the current study confirms that treatment with preservative free tafluprost eye drops is safe and leads to a pronounced reduction in IOP even in patients with IOP levels of 30 mmHg or higher.

In the last years evidence has accumulated that long-term treatment with preservative containing eye drops may have adverse effects on the eye and especially on the ocular surface. Nowadays it is well established that most of the observed side effects are related rather to the concomitant application of preservatives, most importantly to benzalkonium chloride, than to the active ingredient itself. This is also underlined by the observation that most side effects seen in glaucoma patients are more frequent in patients taking preservative containing eye drops compared to those taking preservative free formulations [10].

However, as it is known that benzalkonium chloride acts as a penetration enhancer for drugs into the anterior chamber of the eye, doubts have been raised concerning the clinical efficacy of IOP lowering drugs without preservatives [11]. It has been shown that benzalkonium chloride when added to a topical formulation, increases the penetration of certain compounds through the cornea [12]. It has, however, to be noted that changed penetration of a compound though the cornea does not necessary correlate to its clinical efficacy An experimental study in rabbits has shown that for tafluprost, there is no difference in the penetration into the anterior chamber between benzalkonium chloride containing and preservative free formulations [13]. Still, clinical studies are necessary to assess the IOP lowering potential of preservative free formulations in a clinical "real life" setting. A cross-sectional study investigating the effect of 4 weeks treatment with a preserved and a preservative-free tafluprost formulation in patients with POAG or ocular hypertension found no differences in terms of IOP lowering capacity or safety [14]. Another parallel-group, investigator masked study in patients with POAG or ocular hypertension has shown that latanoprost in a preservative free formulation features the same IOP lowering capacity as the formulation containing benzalkonium chloride, but with better tolerability [15]. Preservative free bimatoprost and travoprost also showed non-inferiority compared to the preservative containing formulations in terms of IOP lowering potential in randomized, double masked studies [16, 17]. Fixed combinations containing no preservatives also have been found to be as effective in lowering IOP as preservative containing formulations. This has been shown in randomized, double masked trials for travoprost $0.004 \% /$ timolol $0.5 \%$-fixed combination as well as for dorzolamide/timolol fixed combination $[18,19]$.

The data from the current study indicate that preservative free tafluprost leads to a pronounced decrease in IOP after a 4 and 8 weeks observation period. In addition, our experiment shows that preservative free tafluprost was well tolerated and no severe side effects were observed.

The European Glaucoma Society states the IOP lowering potential of prostaglandins to be between 25 and $35 \%$ from the initial value [20]. This is in concordance with the present study, where tafluprost decreased IOP in the range of $32 \%$ to $34 \%$ in the selected study population, which corresponds to an absolute IOP decrease of about $10 \mathrm{mmHg}$. This absolute decrease in IOP is slightly higher than observed in other studies investigating the ef- fect of tafluprost on IOP [21-23]. In treatment naïve patients with different forms of open angle glaucoma or OHT, 12 weeks treatment with tafluprost decreased IOP by $28.8 \%$ [24]. A study in a very heterogenous group of 544 patients with glaucoma or OHT found an IOP lowering potential of tafluprost of $21.1 \%$ after 12 weeks treatment. It has to be noted that in this study, $91.8 \%$ of the patients were already under treatment and were either only switched to tafluprost with no wash-out period or tafluprost was added to the existing therapy [25]. When comparing our results with the results of these trials, it has, however, to be mentioned that all of the above mentioned studies included patients with considerably lower IOPs at baseline than in the current study.

One of the strength of the current study is that it was designed to investigate the IOP lowering potential in patients with high intraocular pressures. This is of clinical relevance, given that especially patients with high IOPs require a safe and pronounced IOP lowering therapy. To ensure comparable conditions and to fully assess the IOP lowering potential all patients had to undergo a washout phase of 2-4 weeks. However, because of ethical reasons, the washout phase was limited to a maximum of 4 weeks, which allows for the washout of the drug without posing a risk of long term increase of IOP.

One limitation of our study is that the study lacks a control group. Thus, we cannot determine how the IOP lowering potential of preservative free tafluprost compares to other IOP lowering drugs.

\section{Conclusion}

In conclusion, our results show that in patients with high IOPs preservative free tafluprost is safe and leads to a pronounced decrease of IOP during an 8 week treatment period. Further studies are, however, needed to assess the safety and IOP lowering potential of preservative free tafluprost for long-term treatment of glaucoma.

\section{Acknowledgement}

Financial support from Santen is gratefully acknowledged.

\section{References}

[1]. Quigley HA, Nickells RW, Kerrigan LA, Pease ME, Thibault DJ, et al (1995) Retinal ganglion cell death in experimental glaucoma and after axotomy occurs by apoptosis. Invest Ophthalmol Vis Sci 36 (5):774-86.

[2]. Leske MC, Heijl A, Hyman L, Bengtsson B, Dong L, et al. (2007) Predictors of long-term progression in the early manifest glaucoma trial. Ophthalmology 114 (11):1965-72.

[3]. Heijl A, Leske MC, Bengtsson B, Hyman L, Hussein M, et al. (2002) Reduction of intraocular pressure and glaucoma progression: results from the Early Manifest Glaucoma Trial. Arch. Ophthalmol. 120 (10):1268-79.

[4]. Cracknell KPB, Grierson I (2009) Prostaglandin analogues in the anterior eye: Their pressure lowering action and side effects. Exp. Eye Res. 88 (4):786-791.

[5]. Baudouin C, Labbe A, Liang H, Pauly A, Brignole-Baudouin F (2010) Preservatives in eyedrops: the good, the bad and the ugly. Prog. Retin. Eye Res. 29 (4):312-34

[6]. Iester M, Telani S, Frezzotti P, Motolese I, Figus M, et al. (2014) Ocular Surface Changes in Glaucomatous Patients Treated With and Without Preservatives Beta-Blockers. J Ocul Pharmacol Ther. 30(6): 476-81.

[7]. Stalmans I, Sunaric Megevand G, Cordeiro MF, Hommer A, Rossetti L, et al. (2013) Preservative-free treatment in glaucoma: who, when, and why. Eur J Ophthalmol 23 (4):518-25.

[8]. Nordstrom BL, Friedman DS, Mozaffari E, Quigley HA, Walker AM (2005) Persistence and adherence with topical glaucoma therapy. Am. J. Ophthal- 
mol. 140 (4):598-606.

[9]. Robin AL, Covert D (2005) Does adjunctive glaucoma therapy affect adherence to the initial primary therapy? Ophthalmology 112(5):863-8.

[10]. Jaenen N, Baudouin C, Pouliquen P, Manni G, Figueiredo A, et al. (2007) Ocular symptoms and signs with preserved and preservative-free glaucoma medications. Eur. J. Ophthalmol. 17 (3):341-9.

[11]. Januleviciene I, Siaudvytyte L, Barsauskaite R (2012) Ophthalmic drug delivery in glaucoma-a review. Pharmaceutics 4(1):243-251.

[12]. Rathore MS, Majumdar DK (2006) Effect of formulation factors on in vitro transcorneal permeation of gatifloxacin from aqueous drops. AAPS PharmSciTech 7(3):57.

[13]. Pellinen P, Lokkila J (2009) Corneal penetration into rabbit aqueous humor is comparable between preserved and preservative-free tafluprost. Ophthalmic Res. 41(2):118-22.

[14]. Hamacher T, Airaksinen J, Saarela V, Liinamaa MJ, Richter U, et al. (2008) Efficacy and safety levels of preserved and preservative-free tafluprost are equivalent in patients with glaucoma or ocular hypertension: results from a pharmacodynamics analysis. Acta Ophthalmol Suppl (Oxf) 242:14-9.

[15]. Rouland JF, Traverso CE, Stalmans I, Fekih LE, Delval L, et al. (2013) Efficacy and safety of preservative-free latanoprost eyedrops, compared with BAK-preserved latanoprost in patients with ocular hypertension or glaucoma. Br. J. Ophthalmol. 97(2):196-200.

[16]. Day DG, Walters TR, Schwartz GF, Mundorf TK, Liu C, et al. (2013) Bimatoprost $0.03 \%$ preservative-free ophthalmic solution versus bimatoprost $0.03 \%$ ophthalmic solution (Lumigan) for glaucoma or ocular hypertension: a 12-week, randomised, double-masked trial. Br. J. Ophthalmol. 97(8):98993.

[17]. Lewis RA, Katz GJ, Weiss MJ, Landry TA, Dickerson JE, et al. (2007) Travoprost $0.004 \%$ with and without benzalkonium chloride: a comparison of safety and efficacy. J. Glaucoma 16 (1):98-103.

[18]. Kitazawa Y, Smith P, Sasaki N, Kotake S, Bae K, et al. (2011) Travoprost $0.004 \% /$ timolol $0.5 \%$-fixed combination with and without benzalkonium chloride: a prospective, randomized, doubled-masked comparison of safety and efficacy. Eye (Lond) 25(9):1161-9.
[19]. Shedden A, Adamsons IA, Getson AJ, Laurence JK, Lines CR, et al. (2010) Comparison of the efficacy and tolerability of preservative-free and preservative-containing formulations of the dorzolamide/timolol fixed combination (COSOPT) in patients with elevated intraocular pressure in a randomized clinical trial. Graefes Arch. Clin. Exp. Ophthalmol. 248(12):1757-64.

[20]. (2014) European Glaucoma Society. Terminology and guidelines for glaucoma (4 edtn). Savona, Dogma.

[21]. Kuwayama Y, Nomura A (2014) Prospective observational post-marketing study of tafluprost for glaucoma and ocular hypertension: short-term efficacy and safety. Adv. Ther. 31(4):461-71.

[22]. Mizoguchi T, Ozaki M, Unoki K, Dake Y, Eto T, et al. (2012) A randomized crossover study comparing tafluprost $0.0015 \%$ with travoprost $0.004 \%$ in patients with normal-tension glaucoma. Clin Ophthalmol 6:1579-84.

[23]. Costa VP, Harris A, Anderson D, Stodtmeister R, Cremasco F, et al. (2014) Ocular perfusion pressure in glaucoma. Acta Ophthalmol. 92(4):e252-66.

[24]. Lanzl I, Hamacher T, Rosbach K, Ramez MO, Rothe R, et al. (2013) Preservative-free tafluprost in the treatment of naive patients with glaucoma and ocular hypertension. Clin Ophthalmol 7:901-10.

[25]. Hommer A, Mohammed Ramez O, Burchert M, Kimmich F (2010) IOPlowering efficacy and tolerability of preservative-free tafluprost $0.0015 \%$ among patients with ocular hypertension or glaucoma. Curr. Med. Res. Opin. 26(8):1905-13

Special Issue on

"Glaucoma and Hypertensive Retinopathy"

Edited by:

Dr. Pinakin Gunvant Davey, Western University of Health Sciences, USA

E-mail:pdavey@westernu.edu 